\title{
Is Low Dose Combination Therapy Effective for Migraine Prophylaxis? A Case Series Study
}

\author{
Sina Karamimagham, ${ }^{1}$ Tahereh Poursadeghfard, ${ }^{2}$ and Maryam Poursadeghfard ${ }^{3, *}$ \\ ${ }^{1}$ Department of Pediatrics, Medical School, Shiraz University of Medical Sciences, Shiraz, Iran \\ ${ }^{2}$ Department of Statistics, Islamic Azad University, Firooz Abad Branch, Fars, Iran \\ ${ }^{3}$ Clinical Neurology Research Center, Shiraz University of Medical Sciences, Shiraz, Iran \\ "Corresponding author: Maryam Poursadeghfard, Clinical Neurology Research Center, Department of Neurology, Motahhari Clinic, Nemazee Square, Shiraz, Iran. Tel/Fax: \\ +98-7136121065, E-mail: poursadegh@sums.ac.ir
}

Received 2015 August 09; Revised 2015 November 08; Accepted 2016 September 24.

\begin{abstract}
Introduction: The aim of this case series study was to determine whether the lower starting doses of prophylactic antimigraine drugs are as effective as the recommended standard regimen when used in combination without increment.

Methods: In this retrospective case series study, we reported old charts of previously visited patients with migraine headache who needed prophylaxis in Shiraz, south of Iran. All medications used in these patients were started as combination of two drugs with the lower doses than mentioned in the literature. Descriptive statistics were used for data analysis.

Results: Three patients (7.5\%) did not respond to medications and 7 (18.75\%) showed a very good response (more than $70 \%$ recovery in pain severity). Overall, 29 patients (72\%) responded with at least 50\% recovery after treatment.

Conclusions: Our results showed lower doses of migraine prophylactic drugs can be effective with the least side effects and the most tolerance for patients. This case series report can be useful in designing further studies; however, no causal inferences should be made from it regarding the efficacy of the investigated treatment.
\end{abstract}

Keywords: Migraine, Prophylaxis, Medication

\section{Introduction}

Migraine headache is one of the most common chronic neurologic disorders which affects $13 \%$ of general population $[1,2]$. It is diagnosed by unilateral throbbing headache with nausea, vomiting, photophobia, phonophobia and worsening with daily activity [3]. It usually has a major effect on quality of life and daily performance $[4,5]$. Pharmacologic therapy is divided into acute and prophylactic treatment. Preventive therapy is started when the attacks are so frequent or long, with severe disabling attacks or no response to acute medical therapy [6]. 40 $50 \%$ pain reduction is considered as successful prophylactic treatment [5] and helps to reduce the risk of chronic migraine or medication overuse headache [7]. It has recently been recommended that prophylaxis be continue for at least 6 months and in some patients even until 12 months because many patients may develop worse symptoms if their treatment is stopped sooner $[8,9]$. The most approved agents for migraine prophylaxis are tricyclic antidepressants, betabelackers, anticonvulsants, calcium channel blockers and monoaminooxidase inhibitors [10, 11]. Recommended doses start in a low range with gradu- ally titration base on the patient response [12]. Sometimes, a significant improvement is not seen with monotherapy and limited evidence offers combination therapy in individuals who have had poor response in monotherapy [13].

Many patients do not tolerate the high dose of prophylactic drugs for a long time ( 6 to 12 months) due to adverse effects and have to stop preventive therapy in spite of initial good response, so it is important to design a low dose regimen of medical therapy to increase treatment success and decrease drop-out due to adverse effects.

According to our previous experience, we thought our population may respond to combined lower doses of antimigraine medicine which is a new aspect for migraine prophylaxis; thus, this retrospective case series study was done to determine if continuous low dose therapy with two drugs is effective and tolerable. On the other hand, the primary purpose of this study is to recommend new hypotheses that can subsequently be tested in studies of higher methodological rigor. 


\section{Methods and Patients}

This retrospective case series study was carried out in Imam Reza clinic, a specialty and sub-specialty medical center, affiliated to Shiraz University of Medical Sciences, Shiraz, south of Iran in a 4 months period (2013). Migraine headache is one of the most frequent complaints of the patients who come to general neurology clinic in this area. In our clinic, all of the patients routinely have medical chart in which physical and neurological examination; and medical and drug histories are recorded. For patients with migraine headache, frequency and severity of pain are recorded too in a simple questionnaire. As it was mentioned in the literature, migraine prophylaxis at first should be started with low dose of one drug and gradually increased to either reach the optimal response or the side effects appear. According to our previous experience, we thought our population may respond to combined lower doses of anti-migraine medicine without or with less need for dose increment; so treatment is started and continued with 2 combined medications in the lower doses than mentioned in the literature to control migraine headache. All drugs used in these patients were approved as prophylactic anti-migraine medications.

They are usually prescribed in a regular period of time to consider the treatment response and probable side effects. So all of these patients were planned to have the second visit 3 weeks later to be evaluated for side effects or tolerability and the third visit 8 weeks later as the main endpoint to check their response to prophylaxis; also, the fourth visit was done after the next 4 months to taper the drugs. As a rout, if there is no acceptable response at the end of the 3rd or 8th week, as a standard management, medication doses are gradually increased to achieve the goal of treatment. We retrospectively studied the charts to evaluate if there was good response to concurrent 2 drugs therapy without increasing the primary starting dose. In a 4-month period, we included all patients' charts that had inclusion criteria, were referred for current migraine headache, and needed migraine prophylaxis, both common and classic types. We chose the chars of patients who had completed the duration of follow-up at the third visit (8th week) and filled their questionnaire out.

Inclusion criteria were as follows:

1) Having international headache society's (IHS) criteria [14] for migraine headache.

2) Having at least 2 attacks of migraine headache a week or 3 attacks a month.

3) Not receiving prophylaxis for migraine headache during the previous 6 months.

And exclusion criteria:
1) Using any type of psychiatric drugs as SSRI or benzodiazepines during the treatment or suffering from a major psychiatric problem at that time.

2) Concurrent medical illnesses or consumption of any other medications (antihypertensive, antiepileptic).

To determine the severity of the headache, pain rating scale of the British pain society (2006) was used [15]. It is a questionnaire which describes pain intensity, degree of pain distressing and interfering with normal daily activities. It is quantified by numbers 0 to ten. 0 represents the least and 10 represents the most effects of pain on the person. In the first visit, the patients were guided to complete the questionnaire. All drugs chosen for these patients were approved as prophylactic anti-migraine medications but used in a lower dose than mentioned in the literature to control the migraine headache [16] (nortriptyline, propranolol, depakine) (Table 1). All the patients received combination of 2 drugs according to their condition; on the other hand, they had been individualized according to their age, co-morbid and concurrent medications usage. 20 patients received depakine/propranolol, and 20 received nortriptyline/propranolol.

Table 1. Comparison of Drugs and Their Doses for Migraine Prophylaxis in This Study and Standard Regimen

\begin{tabular}{lcc}
\hline Drugs & Dose, $\mathbf{m g} /$ day, In This Study & Standard Dose, $\mathbf{m g} /$ day \\
\hline Nortriptyline & 25 & $10-150$ \\
Depakine & 500 & $500-1750$ \\
Propranolol & $20-30$ & $80-240$ \\
\hline
\end{tabular}

For statistical analysis, SPSS software version 18 was used. As the design of a case series is descriptive, only descriptive statistics were used.

\section{Results}

Of 40 patients, $3(7.5 \%)$ were male and 37 (92.5\%) female. The youngest patient was 9 and the oldest 67 years old. Most of our patients were in their twenties (21 to 30) (Figure 1$)$.

$2(5 \%)$ patients had classic migraine with aura and 38 (95\%) had common migraine. There were significant drug side effects in $2(5 \%)$ patients in need of changing medication. The first one suffered hair loss and weight gain after depakine consumption and the second one developed severe hypotension (propranolol).

According to pain relief, we divided the patients into 4 groups: no significant response ( $0-10 \%$ pain relief), very low response $(10-30 \%)$, low response (30 - 50\% pain relief), good response (50 - 70\% pain relief) and very good 


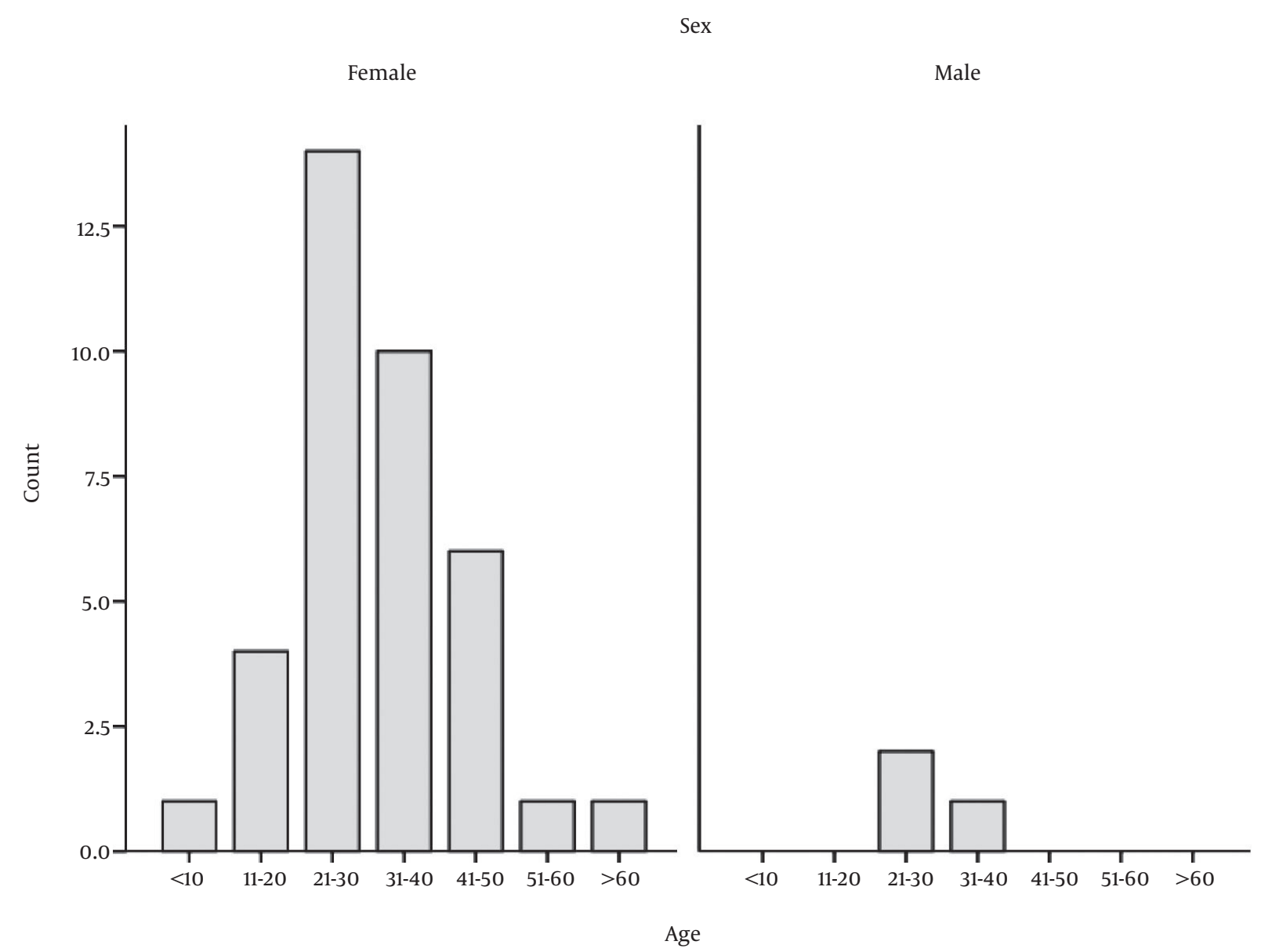

Figure 1. Number of Patients Per Each 10-Years Age Group According to Sex

response (above $70 \%$ pain relief). Three out of the patients (7.5\%) did not respond to medications and 7 patients (18.75\%) showed a very good response to low dose of antimigraine prophylactic drugs. Overall, 29 patients (72\%) responded $50 \%$ or more to treatment, (95\% confidence interval, 67.6 to 76.4 ) (Figure 2).

\section{Discussion}

Our results were consistent with $96 \%$ common and $4 \%$ classic migraine and the majority of our patients were female. According to literature, common migraine is more prevalent than classic migraine (90\% versus $10 \%$ ) [17]. It is also more common and more painful in females' population [18] similar to what was seen in our study.

When migraine prophylaxis is started, it should be based on some considerations (burden of migraine, side effects or disadvantage of medications, co-morbidity and contraindications, drug tolerance, duration of prophylaxis and cost of treatment) [19, 20]. Because of many factors can affect the patients compliance and tolerance especially when it is necessary to use for a long time (6-12 months). Side effects are the most important factor that should be noted (dizziness, drowsiness, weight gain and fatigue). Cost of medications is also a problem that can influence the patient s adherence [21]. So the least effective dose of any kind of drugs can decrease not only the side effects but also the cost of treatment.

Thus, it is important to choose drugs and also doses with most acceptability for patients because based on some reports prophylactic drugs for migraine headache are supposed to be underutilized by patients [22]. In the study by Mc Kol and co-worker (2008), from 55\% of patients who were eligible for migraine prophylaxis, only $8 \%$ actually continued their treatment [23]. Therapy ought to start at low dose and then gradually increase for minimizing ad- 


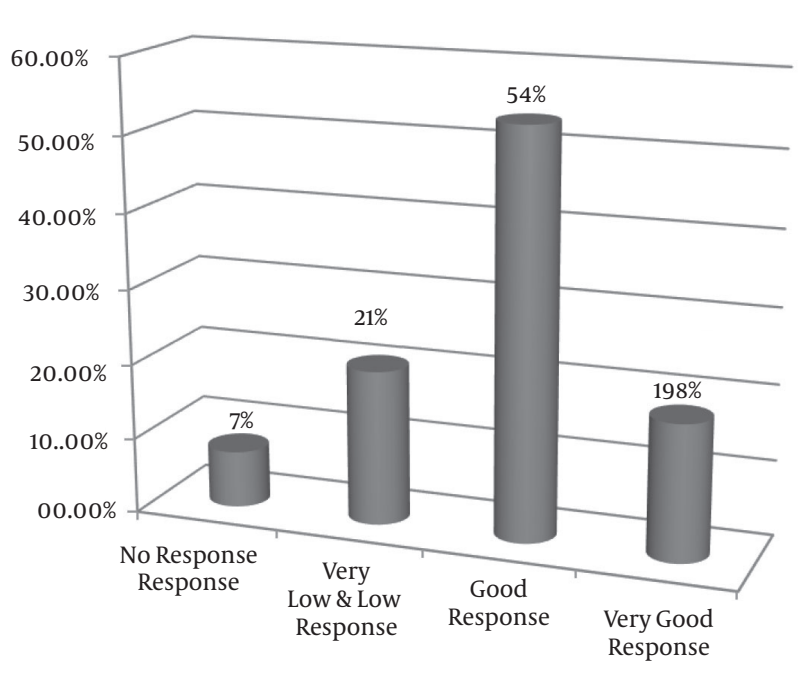

Figure 2. Response to Medication After 2 Months of Follow up

verse effects. Finally the lowest effective dose is the goal of treatment [24].

In this case series study, preventive therapy had been done and continued at a dose lower than usually recommended; all of our patients received two drugs combination therapy. However, most of the patients (72\%) had favorite response (more than 50\%). There were significant side effects only in $2(5 \%)$ patients who needed to change medication and the other ones had no or mild and transient problem with their medications. Combination therapy in low dose did not have any additive adverse effect.

Some data are available that suggest the efficiency of lower dose compared with higher doses. Domingues and colleague (2009) found that combination of low dose propranolol (40 mg / day) and nortriptyline (20 mg / day) is effective for migraine prophylaxis without more intolerance or higher rate of side effects [25]. One report in 2006 explained two trials done on topiramate and placebo and showed that the best result for migraine prevention was achieved both in $100 \mathrm{mg} /$ day and $200 \mathrm{mg}$ / day topiramate with no difference in efficacy [26]. In another study (Dib 2008) on valproate and placebo, fixed dose of $500 \mathrm{mg} / \mathrm{day}$, $1000 \mathrm{mg}$ / day and $1500 \mathrm{mg}$ / day had similar efficacy and the recommended dose for most patients was $500 \mathrm{mg} /$ day [27].

We hypothesized that in some population lower dose can make an acceptable response via different ways, for example slower drugs metabolization in these individuals; however further studies are needed.

Regarding Domingues report [25], we supposed combination therapy have more advantage with different pharmacologic effects and this can be safe if it is used in low dose. It is more acceptable and tolerable for patients to complete the course of preventive therapy.

Nevertheless, further studies are required to approve the effectiveness of low dose combined regimen for migraine prophylaxis. We hope this report can assist the researchers to design future trials to document a new concept whenever migraine prophylaxis is required.

\subsection{Limitations}

This Study Had Some Limitations Such as:

1. It is better to be a prospective case control study rather than case series. But we hope it will be a starter for a designed survey about migraine headache prophylaxis.

2. Small number of patients and short period of study.

3. We did not study low dose monotherapy as compared with the usual standard dose which generally is recommended.

4. The main focus was on severity of headache rather than on frequency or duration of headache.

\subsection{Conclusion}

If patients are carefully selected for migraine prophylaxis, lower (than usual) doses of medications can be effective with the least side effects and the most tolerance for patients. Also combination therapy may have more advantages with different pharmacologic effects and can be safe if it is used in low dose. However, no causal inferences should be made from it regarding the efficacy of the investigated treatment.

\subsection{Recommendation}

As migraine headache is a frequent and disabling complaint of patients referred to neurology clinic, it is logical to choose the most effective with the least side effect prophylaxis regimen. So we recommend a well-designed randomized control trial study to better evaluation of low dose combination therapy in migraine headache.

\section{Acknowledgments}

The authors would like to thank Dr. Nasrin Shokrpour at Center for development of clinical research of Nemazee hospital for editorial assistance. Code number of project: 95-01-94/12375 


\section{Footnotes}

Authors' Contribution: Primary conception and design of the work, primary drafting of the article, final approval of the article, Maryam Poursadeghfard; critical revising of the article and final approval of the article, Sina Karamimagham; Data gathering, interpretation and analysis, Tahereh Poursadeghfard.

Funding/Support: Shiraz University of Medical Sciences, Shiraz, Iran.

\section{References}

1. Silberstein SD, Dodick D, Freitag F, Pearlman SH, Hahn SR, Scher AI, et al. Pharmacological approaches to managing migraine and associated comorbidities-clinical considerations for monotherapy versus polytherapy. Headache. 2007;47(4):585-99. doi: 10.1111/j.15264610.2007.00760.x. [PubMed: 17445108].

2. Pascual J. Recent advances in the pharmacological management of migraine. F1000 Med Rep. 2009;1(39).

3. Kelman L. Migraine changes with age: IMPACT on migraine classification. Headache. 2006;46(7):1161-71. doi: 10.1111/j.15264610.2006.00444.x. [PubMed: 16866720].

4. Bahrami P, Zebardast H, Zibaei M, Mohammadzadeh M, Zabandan N. Prevalence and characteristics of headache in Khoramabad, Iran. Pain Physician. 2012;15(4):327-32. [PubMed: 22828686].

5. Holroyd KA, Cottrell CK, O'Donnell FJ, Cordingley GE, Drew JB, Carlson BW, et al. Effect of preventive ( blocker) treatment, behavioural migraine management, or their combination on outcomes of optimised acute treatment in frequent migraine: randomised controlled trial. Bmj. 2010;341(sep29 2):4871. doi: 10.1136/bmj.c4871.

6. Zencirci B. Comparison of the effects of dietary factors in the management and prophylaxis of migraine. J Pain Res. 2010;3:125-30. [PubMed: 21197315].

7. Lipton RB, Bigal ME, Diamond M, Freitag F, Reed ML, Stewart WF, et al. Migraine prevalence, disease burden, and the need for preventive therapy. Neurology. 2007;68(5):343-9. doi: 10.1212/01.wnl.0000252808.97649.21. [PubMed: 17261680].

8. Diener HC, Agosti R, Allais G, Bergmans P, Bussone G, Davies B, et al. Cessation versus continuation of 6-month migraine preventive therapy with topiramate(PROMPT): a randomised, double-blind, placebocontrolled trial. Lancet Neurol. 2007;6(12):1054-62. doi: 10.1016/S14744422(07)70272-7. [PubMed: 17988947].

9. Pascual J, El Berdei Y, Gomez-Sanchez JC. How many migraine patients need prolonged ( $>1$ year) preventive treatment? Experience with topiramate.J Headache Pain. 2007;8(2):90-3. doi: 10.1007/s10194-007-0351x. [PubMed: 17221343].

10. Pompili M, Serafini G, Innamorati M, Serra G, Dominici G, FortesLindau J, et al. Patient outcome in migraine prophylaxis: the role of psychopharmacological agents. Patient Relat Outcome Meas. 2010;1:107-18. doi: 10.2147/PROM.S9742. [PubMed: 22915957].
11. Modi S, Lowder DM. Medications for migraine prophylaxis. Am Fam Physician. 2006;73(1):72-8. [PubMed: 16417067].

12. Evers S, Afra J, Frese A, Goadsby PJ, Linde M, May A, et al. EFNS guideline on the drug treatment of migraine - report of an EFNS task force. Eur J Neurol. 2006;13(6):560-72. doi: 10.1111/j.1468-1331.2006.01411.x. [PubMed: 16796580].

13. Krymchantowski AV, da Cunha Jevoux C, Bigal ME. Topiramate plus nortriptyline in the preventive treatment of migraine: a controlled study for nonresponders. J Headache Pain. 2012;13(1):53-9. doi: 10.1007/s10194-011-0395-4. [PubMed: 22008899].

14. Headache Classification Subcommittee of the International Headache Society. 2 ed. 24. Cephalalgia: The International Classification of Headache Disorders; 2004. pp. 8-160.

15. Pain Rating Scale. The British Pain Society [internet]. Charity no. 1103260 2006. Available from: http://britishpainsociety.org/pain_ scales_english.pdf.

16. Boes CJ, Capobianco DJ, Cutrer FM, Dodick DW, Garza I, Swanson JW. Headache and other craniofacial pain. In: Bradley WJ, Daroff RB, Fenichel GM, Jankovic J, eds. Neurology in clinical practice. 5 ed. Philadelphia PA: Elsevier; 2008. pp. 2037-8.

17. Gobel H. Botulinum toxin in migraine prophylaxis.JNeurol. 2004;251 Suppl 1:I8-11. doi: 10.1007/s00415-004-1103-y. [PubMed: 14991336].

18. Sullivan E, Bushnell C. Management of menstrual migraine: a review of current abortive and prophylactic therapies. Curr Pain Headache Rep. 2010;14(5):376-84. doi: 10.1007/s11916-010-0138-2. [PubMed: 20697846].

19. Dekker F, Knuistingh Neven A, Andriesse B, Kernick D, Reis R, Ferrari $\mathrm{MD}$, et al. Prophylactic treatment of migraine; the patient's view, a qualitative study. BMC Fam Pract. 2012;13:13. doi: 10.1186/1471-2296-1313. [PubMed: 22405186].

20. Loj J, Solomon GD. Migraine prophylaxis: who, why, and how. Cleve Clin J Med. 2006;73(9):793-4-800-1 passim. [PubMed: 16970133].

21. Cady R, Schreiber C. Botulinum toxin type A as migraine preventive treatment in patients previously failing oral prophylactic treatment due to compliance issues. Headache. 2008;48(6):900-13. doi: 10.1111/j.1526-4610.2007.00953.x. [PubMed: 18047501].

22. Pringsheim T, Davenport WJ, Becker WJ. Prophylaxis of migraine headache. CMAJ. 2010;182(7):269-76. doi: 10.1503/cmaj.081657. [PubMed: 20159899].

23. Kol CM, Dekker F, Neven AK, Assendelft WJ, Blom JW. Acceptance or rejection of prophylactic medicine in patients with migraine: a cross-sectional study. Br J Gen Pract. 2008;58(547):98-101. doi: 10.3399/bjgp08X264063. [PubMed: 18307853].

24. Garza I, Swanson JW. Prophylaxis of migraine. Neuropsychiatr Dis Treat. 2006;2(3):281-91. [PubMed: 19412475].

25. Domingues RB, Silva AL, Domingues SA, Aquino CC, Kuster GW. A double-blind randomized controlled trial of low doses of propranolol, nortriptyline, and the combination of propranolol and nortriptyline for the preventive treatment of migraine. Arq Neuropsiquiatr. 2009;67(4):973-7. [PubMed: 20069203].

26. Bigal ME, Krymchantowski AV. Emerging drugs for migraine prophylaxis and treatment. MedGenMed. 2006;8(2):31. [PubMed: 16926770].

27. Dib M. Optimizing prophylactic treatment of migraine: Subtypes and patient matching. Ther Clin Risk Manag. 2008;4(5):1061-78. [PubMed: 19209286]. 